REVIEW

\title{
The direction of mental health care for the elderly
}

A Barker

Postgrad Med J 2004;80:187-189. doi: 10.1136/pgmj.2002.003731

The way that mental health care for older people is developing in the UK is being shaped by a number of factors. These include demographic shifts, changes in the general population's attitudes to health, alterations in professional practice, governmental policy, and medical and technological advances. This article summarises some key aspects of these changes and predicts the likely direction of growth of mental health services in response.

\section{POPULATION}

Data from the 2001 census confirm that the population is getting older. ${ }^{1}$ The number of people aged over 60 years now exceeds the number of people under 16 years of age, and by 2014 the number of people aged over 65 will outnumber those aged under 16 . The number of people aged over 85 years has tripled in the last 40 years. Although those interested in care of the elderly pursue the ideal of "squaring the life curve" - extending healthy life with a shortened period of functional disability-this does not appear to be happening yet, as the number of disabled years is increasing along with the overall lifespan. These factors together are likely to mean that there are more elderly people requiring care and fewer younger people to look after them. Thankfully the trend of people being less likely to live in couples is not true for those aged over 65 , for the next 20 years at least. ${ }^{2}$ However, these demographic changes provide a major challenge to the NHS and social services, and have implications for the way that services are run and funded. Services will need to be better at attracting employees and be designed so as to be carer efficient. It is likely that the State will become more involved in determining the financing of long term care, either through central funding or through promoting insurance based schemes.

\section{PERSON}

With the information revolution and the rise of consumerism in health care, older people are becoming both more knowledgeable and more assertive in demanding effective services. Service users are expecting to have a say in designing services and in choosing treatments and the setting in which these are delivered. Service providers for people with dementia have been more paternalistic in their approach than their colleagues in general psychiatry, though this is changing. Tom Kitwood's work in highlighting the "personhood" of dementia ${ }^{3}$ coincided with a greater acknowledgement of the importance of person centred services in the NHS, and there is now a greater awareness that people with dementia require information about their diagnosis and prognosis. ${ }^{4}$ We can expect the use of advance directives to increase. The improvement in the rights of people with dementia is likely to extend to carers having a greater say in their health care if the intended bill on mental capacity is passed by parliament later this year.

The introduction of antidementia drugs over the past few years has meant that there is now a greater recognised need to refer people earlier in the disease process. More people with greater insight and awareness are being referred, and services are having to consider the need for diagnostic counselling. The supply of information to both carers and patients was highlighted as being lacking in the Audit Commission report on mental health services for the elderly. ${ }^{5}$

\section{POLICY}

The overall direction of NHS policy in England is in line with the prime minister's four principles for developing the pubic sector. These comprise setting national standards and inspection processes with independent regulatory bodies, ensuring devolution and delegation to the front line, promoting plurality of providers, and giving choice to users.

The NHS plan ${ }^{6}$ started an ambitious programme of investment and reform of the NHS, with a series of national service frameworks (NSFs) following. Mental health in older people appeared not in the mental health NSF but in the NSF for older people. ${ }^{7}$ The NSF for older people aimed to assure standards of care, extend access to services, develop those services that promote independence, help people to stay healthy, and develop better links between health, social services, and other agencies.

Although the mental health standard of the NSF for older people was widely welcomed for its content, there was concern over the lack of hard targets that would help to prioritise this area.

One of the first targets set in the NSF for older people was a review of all written policies by all NHS trusts for evidence of ageism. This revealed little explicit ageism, though the harder task will be for scrutiny committees to uncover and remedy indirect ageism in patterns of service delivery. In mental health services this is most evident in psychological therapies and liaison psychiatry, where services are often much more comprehensive for adults of working age than for older people, despite there being no evidence of greater benefit.

Amidst criticism about the number of targets being set within the NHS plan ${ }^{6}$ and NSFs, the planning and priorities framework, published in 
2002, rationalised and prioritised some of these targets. ${ }^{8}$ This document highlighted the importance of access and capacity as prime targets for service reorganisation, and in the short term it is the services most obviously related to acute hospitals (for example, liaison psychiatry) and those community services aiming to avoid admission to hospital and to facilitate discharge by "whole systems" working that are most likely to be promoted. Ultimately, 24 hour multidisciplinary and multiagency teams will become the norm, with consultants playing an important part in the leadership and supervision of the workers in these teams, being personally involved where complex cases or legal issues require their attention. This will lead to a greater awareness of mental health issues in the elderly by primary care and social care staff. More use of pooled budgets will be seen. A broader definition of health will become accepted, with local authorities (welfare, benefits, housing, and leisure), social services, and primary and secondary care working in true partnership. A greater role for local communities in setting the health agenda and monitoring service effectiveness will develop. Those services where a specialist function is hardest to justify (psychiatric day hospital versus day care, hospital respite versus self paying private sector care) are most vulnerable to loss.

Another interesting development in the UK, which may have implications for the direction of mental health care, is the piloting by the NHS national primary and care trust development programme of the "evercare" approach to disease management. An unpublished independent evaluation of this approach, developed by the US based healthcare maintenance organisation United Health Group, demonstrated a $50 \%$ reduction in hospitalisation rate, while achieving the same mortality results as a control group, a significant reduction in the number of prescription drugs an elderly patient takes, while maintaining health, and a $97 \%$ satisfaction rating among families, together with an extremely high satisfaction rating among doctors. The service model aims to be person centred and holistic, to deliver care in the least invasive manner in the least invasive setting, and to promote maximum function, independence, comfort, and quality of life. A core element of this approach is a comprehensive initial assessment, which includes detailed development of advance directives, indicating what future healthcare interventions are desired or not desired. This piloting comes at a time when a mental capacity bill is to be presented to parliament that would give increased powers over healthcare decisions to advocates acting on behalf of people with insufficient mental capacity.

\section{PROFESSIONALISM AND PRACTICE}

Old age psychiatry came of age when it was set up as a specialty within the Royal College of Psychiatrists some 30 years ago and now flourishes as a faculty within the college. This split from general psychiatry and the placing of mental health for the elderly in the NSF for older people rather than in the NSF for mental health have accentuated its uniqueness. However, this has produced something of an identity crisis for those practising it. Are their services now considered to be psychiatry or elderly care? If stamping out ageism is so crucial, how can we have geriatric medicine and old age psychiatry as specialties? The specialty will strengthen its educational and training links with general psychiatry, though in service terms it will increasingly find itself aligned with generic older people's services.

With an expanding workforce (the number of consultants working in mental health care for the elderly has increased from 240 to 370 in the last five years) there are now possibilities for subspecialisation, and memory clinic work and liaison psychiatry are obvious candidates. With greater awareness of mental illness in later life and greater crossagency working there will be a greater requirement for specialists to train generic workers. This is perhaps nowhere more obvious than in general hospitals, where over half of some inpatient populations have concomitant mental illness but where there is evidence of underdiagnosis and suboptimal treatment. ${ }^{9}$ With the increasingly difficult access and capacity targets being set for general hospitals, this is an area that is well placed for future development.

\section{PHARMACEUTICALS}

The last 20 years have seen a dramatic advance in effective and well tolerated psychotropic medications for older people. First came the selective serotonin reuptake inhibitors and a variety of classes of drugs that similarly worked by targeting neurotransmitter systems effectively with fewer unwanted side effects. Next came advances in antipsychotic treatments that were effective while markedly reducing the side effects of sedation, Parkinsonism, tardive dyskinesia, postural hypotension, and confusion, which had limited their usefulness.

The breakthrough that has really changed the direction of mental health care in the elderly in the last decade though has been the development of the cholinesterase inhibitors. These have been recommended by the National Institute for Clinical Excellence for the treatment of mild to moderate Alzheimer's disease, ${ }^{10}$ and trials have been published demonstrating their positive effects in severe Alzheimer's disease, vascular dementia, and dementia with Lewy bodies. The National Institute for Clinical Excellence is currently reviewing its guidance on these indications. This has shifted practice more markedly than has any other development, providing an incentive for general practitioners to detect and refer patients earlier and for services to change to meet the needs of this new patient population. Psychosocial services for people with mild dementia are an example of this.

There are a large number of anti-Alzheimer's medications in development, which aim to modify the disease process by targeting beta amyloid production, hyperphosphorylation of tau, or neurotrophic growth factors. However, a vision of the future is emerging in which we can hope to eradice Alzheimer's disease altogether. There was great excitement when the results of vaccine studies in an animal model of Alzheimer's disease showed a reduction not only in the deposition of beta amyloid ${ }^{11}$ but also in cognitive impairment in treated animals. ${ }^{12}{ }^{13}$ Human trials were discontinued owing to an unacceptable incidence of meningoencephalitis, ${ }^{14}$ though a postmortem examination of one such patient revealed that large sections of the cerebral cortex were devoid of beta amyloid, ${ }^{15}$ and the way is open to modify this technique with potentially far reaching consequences.

The other main area of preventative management of dementia concerns the second commonest cause of dementia-cerebrovascular disease. This area has been neglected, with physicians concentrating on stroke prevention and psychiatrists focusing on palliative care of dementia sufferers. Closer collaboration between stroke specialists, psychiatrists, and general practitioners, focusing on the primary and secondary prevention of stroke, will further reduce the prevalence of vascular dementia. The new general practitioner contract, with its quality indicator on stroke prevention through the establishment of a stroke register and the management of hypertension and other risk factors for stroke, offers considerable promise in this area.

\section{PROSTHETICS AND NEW TECHNOLOGIES}

As well as more effective pharmacological interventions, the other area that will see great development over the next decade is the use of information technology to support people 
with dementia living in their own homes. The shortage of community carers, the wish of older people to remain in their own homes for as long as possible, and the cost implications of long term residential care are making this approach ever more attractive. With technology advances such as "blue tooth" connectivity and with hardware prices falling, the limiting factor is increasingly the imagination of designers. From aids that prompt medication compliance, through lights that turn on if the person gets out of bed, to sensors that can detect the pattern of fridge use to determine whether someone is eating healthily, the possibilities are endless. Telecare systems will link vulnerable adults to community support teams. Interested readers are referred to the enable project (www.enableproject.org) or the Gloucester smart house (www.dementia-voice.org.uk/Projects/Projects GloucesterProject.htm) for further information.

\section{CONCLUSION}

Enormous demographic, political, and technological changes are occurring, which are already affecting the way that services are delivered to older people with mental health problems. However, amidst these changes, the core roles of health professionals working in this field will remain the same: educating others in complex medical and psychosocial evidence based care, advocating for those without a voice, and providing continuity of care for people with mental illness and their carers to enable them to live their lives as fully as possible.

Potential conflict of interest: Dr Barker is seconded to the Department of Health for 1.5 days per week as a professional adviser on mental health issues in the elderly.

\section{REFERENCES}

1 Office for National Statistics. Census 2001: national report for England and Wales. London: Office for National Statistics, 2002.

2 Office for National Statistics. Population Trends 91. London: Office for National Statistics, 1998.

3 Kitwood T. Dementia reconsidered: the person comes first. Maidenhead: Open University Press, 1997.

4 Rice K, Warner N. Breaking the bad news: what do psychiatrists tell patients with dementia about their illness? Int J Geriatr Psychiatry 1994;9:467-71.

5 Audit Commission. Forget me not: mental health services for older people. London: Audit Commission, 2000.

6 Stationery Office. The NHS plan: a plan for investment, a plan for reform. London: Stationery Office, 2000.

7 Department of Health. National service framework for older people. London: Department of Health, 2001.

8 Department of Health. Improvement, expansion and reform-the next 3 years. Priorities and planning framework 2003-2006. London: Department of Health, 2002.

9 Holmes J, Bentley K, Cameron I. Between two stools: psychiatric services for older people in general hospitals. Report of a UK survey. Leeds: University of Leeds, 2002.

10 National Institute for Clinical Excellence. Guidance on the use of donepezil, rivastigmine and galantamine for the treatment of Alzheimer's disease. Technology appraisal guidance No 19. London: National Institute for Clinical Excellence, 2001.

11 Schenk D, Barbour R, Dunn W, et al. Immunization with amyloid- $\beta$ attenuates Alzheimer-disease-like pathology in the PDAPP mouse. Nature 1999;400:173-7.

12 Janus C, Pearson J, McLaurin J, et al. A $\beta$ peptide immunization reduces behavioural impairment and plaques in a model of Alzheimer's disease. Nature 2000;408:979-82.

13 Morgan D, Diamond DM, Gottschall PE, et al. A $\beta$ peptide vaccination prevents memory loss in an animal model of Alzheimer's disease. Nature 2000;408:982-5.

14 Birmingham K, Frantz S. Set back to Alzheimer vaccine studies. Nature Med 2002;8:199-200.

15 James AR, Nicoll D, Wilkinson C, et al. Neuropathology of human Alzheimer disease after immunization with amyloid- $\beta$ peptide: a case report. Nature Med 2003;9:448-52. 